\title{
Fire Safety Research and Measures in Schools in Belgium
}

\author{
A. F. VAN BOGAERT \\ State School Building Fund \\ Ministry of Education \\ B-1040 Brussels, Belgium
}

\section{ABSTRACT}

Starting from an analysis of the fire safety concept, this paper describes the scope, philosophy, methods and results of a radical fire safety research done by the Belgian School Building Fund in the larger framework of an overall school building research to meet the new requirements resulting from important educational evolutions.

While covering three main groups of items : flre preventive, fire restrictive and fire protective measures, it stresses the need

- to take the human behaviour as a starting-point,

- to pre-calculate the evacuation times from the design stage onwards,

- to care for handicapped pupils in regular schools,

- of particular safety concern in special schools and homes for disabled children,

- to take safety arrangements for impaired visitors to the school as a community centre during offhours.

The paper points to some near future developments in school life risks and responding measures.

It is noteworthy that in 1982 the results of this research were translated into a national Belgian norm (NBN) : S 21-204, that was given force of law by Royal Act.

The conclusion says that we bulld schools in a much safer way than we live in them, owing to shortcomings in education itself, and thus ironically wonders why we should build schools.

$$
* * *
$$

Key words : Belgian norm; boarding schools; building design, disabled pupils; evacuation; fire prevention; fire protection, fire restriction; fire safety; safety concept; schools; special schools.

\section{INTRODUCTION}

Up to 1974, the ministry of Public Works was responsible for school building and maintenance. Owing to a shift in departmental tasks, this charge was transferred to the School Building Fund (SBF) of the Education department. Facing the burden of future new qualifications and responsibilities, the SBF 
felt the need to rethink the entire school building problem, going down to, and then starting from, the very essence of functions, needs and conditions in the educational process.

In this research work, fire safety took an important sector closely linked with building layout, with equipment policy and with daily educational activities. The down to the roots research produced an

\section{ANALYSIS OF THE FIRE SAFETY CONCEPT}

Fire safety in a school is a complex notion because it depends on some constant and many alterable factors :

- the design and construction of the building (constant factor)

- the contents of the building (variable factor)

- the occupants' behaviour (highly variable factor)

1.1. The users' daily avocations breed a multicellular mosaic of hazards which are constantly challenging safety in the building. Prospect and caution, prevention habits, self discipline, drilled preparedness and trained co-operation are the positive poles of sound safety behaviour. Age, mental and physical condition, education, assimilated information and applied experience together draw the daily safety diagram of a community.

1.2. The contents in their turn relate to the occupants' activities and to their mental and physical abilities. These activities of ten require apparatus, machines, equipment, furniture and stocks that may hide unsuspected fire and associated risks such as smoke and toxic gas generation. Thorough maintenance and regular checking are preventive measures against these dangers.

1.3. Finally the bujlding, as a solid environment, holds and protects its contents and the human activities. In its design and construction it should closely match all the dimensions of these functions, including those which aim at fire safety. Research of these functions should start with measuring harays originated by the dally activities in the premises and with the prospect of human abilities and fallures on the threshold of a disaster. According to these risks, fire preventive, fire restrictive and fire protective settings should be included in the building and be considered from the very start of design operations.

1.4. Diagram 1 shows an analysis of the three main components into their respective factors, their interactions, and their final impact on the safety level of a school. It clearly indicates that all fire safety research and development work should start from the human factor, because the users'abilities and shortcomings must be matched by the physical setting (Ref. 1). This conclusion became the basic philosophy for the research work on firesafe school building.

\section{SCOPE OF THE RESEARCH}

As said before, this research was part of an overall study in view of an important shift in departmental qualifications. A the same time it was connected with the renovation trends in educational objectives and structures and in didactic means and methods. General new characteristics gradually appeared in school life: increased movement of pupils due to frequent alterations in group size and composition; intensified use, both by teachers and pupils, of electric and electronic apparatus; longer students' self governed occupancies; 


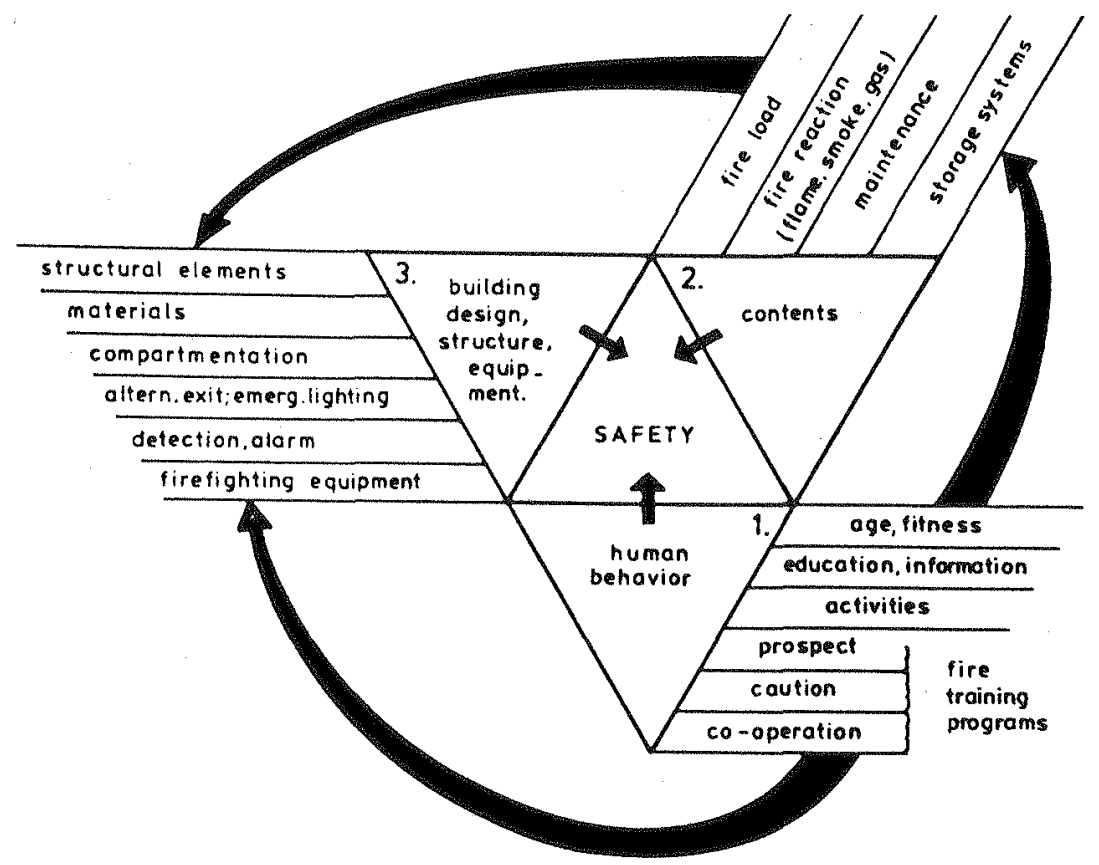

Diagram 1 : Components of the SAFETY notion; logical growth philosophy of fire prevention norms.

use of screens for isolating team work; introduction of lighter furniture allowing immediate re-arrangements for varying activities.

This evolution required new adequate approaches to school building. These were : more diversity in the capacity of rooms, varying from 6 to more than 100 pupils; larger teaching and smaller circulation areas, more compact layout, requiring mechanical ventilation in the core; folding partitions allowing flexibility in space use, increased storage, multiplication of rooms needing gas and electric connexions etc. (Ref. I and 2). It was clear that all thesefeatures would enta11

higher fire-load,

increased energy-risks,

intenser potentiality of smoke generation and

more complicated evacuation.

\section{RESEARCH AND RESULTS}

The research covered three main groups of items : fire preventive, fire restrictive and fire protective measures.

3.1. PREVENTION mainly focussed on the general layout. In fact, prevention became an integrated part of the design work avoiding to locate risky spaces in the core of the building, but pushing towards the skin of the building, or even outside in separate premises such spaces as the boiler room, the school 
kitchen, important storage rooms, tension transformer cabins, workshops. As far as the operational context allows, gas and power equipped rooms are grouped, thus reducing the spread of special equipment risks. If this cluster is conceived in vertical sense, the laboratories are put on the highest floor, in ordex to limit expansion to other floors in case of explosion or of fire followed by explosions.

Another prevention matter lies in the choice of building materials. Not only their fire related properties are important, but also the way they are applied. For, properly speaking, there are rather few dangerous building materials, but many materials are used or applied in hazardous manners.

A third prevention measure aims at limiting risks during offhours : a11 workshops and laboratories have, next to their entrance, a general gas stop cock and an electric key switch, both commanding a 11 conducts inside. Parallel to this, the teacher's desk in laboratories is equipped with devices enabling him, at the slightest incident, to cut off all gas and electricity conducts used by the students.

The same prevention idea prevails in rooms without constant human presence and holding inflammable goods. They are controlled by smoke detectors (in most cases) and heat detectors (in boiler houses). In the latter case they command automatic extinguishing devices.

3.2. The EIRE RESTRICTIVE research mainly concentrated on three items: fire resistance of structural elements, fire reaction of materials, compartmentation.

Fire resistance: In case of fire, the structural elements should maintain their loadbearing or space separating function long enough to allow complete evacuation and adequate firefighting without a threat of crash. The fire resistance requirements are determined by the nature, function and position of the structural elements. Thus the longest fire resistance is required for three types of elements,

- the lst being the skeleton and the floors, because of their impact on the stability of the building;

- the 2nd being the compartmentation walls, the stairs and their encasing, on behalf of their life protective importance;

- the 3rd being the enclosures of risky places like boiler rooms and kitchens.

A second factor influencing the fire resistance requirements is the height of the building, and a third factor is related to the building's nature : on behalf of their night occupancy, boarding schools and students' homes require a higher fire resistance degree from their structural elements than equally-sized schools.

Thus, fundamental fire resistance values of structural elements in school buildings vary from $1 / 2 \mathrm{~h}$ to $2 \mathrm{~h}$.

A second fire restrictive measure concerned materials for floor, ceiling and wall finishes, particularly in relation to their flame spread rate and their potential gas and smoke generation. This was probably the most daunting part of our research work : on one hand we wanted to get rid of the harsh, severe, impersonal interiors of our own schooldays. We were eager to introduce gayer colours, cosier floors, more homelike finishings. On the other hand at that moment the tapestry, carpeting and wall paint markets were flooded with new materials, preponderantly, the fire reactions of which were largely divergent, unsufficiently known and over-advertised in optimistic terms. As we didnot want to buy heavens of nocious gases in pretty pink boxes, a long term contract was 
made with a specialized fire control organism charged to collect laboratorytested information on all present and future floor, wall and ceiling coverings on the Belgian market, and to conclude, for each material, whether it was fit or not to be applied in schools and students' homes. Later on, the study was extended to textile, with a stress on synthetics as used in bedroom equipment.

It was an expensive operation, but the price was well worth the purchase. Not only it provided us with reliable information, but the manufacturers have become conscious that safety research and application should be indispensable and integrated parts of their production.

As to compartmentation, the main fire restrictive measure, a conflict came up with the need of a wide diversity in room spaces and a flexible use of the building. It was felt that permanent evolution in the nature of education would probably call for later serious interior remodelling works. So, restricted compartments would go against adaptability of the building, leaving it physically sound, but functionally obsolete after a couple of decades (Ref. $1 \& 2$ ). Extensive compartments might increase risks but were indispensable to ensure future adaptability to the ever changing educational needs. Once again, moveable education, requiring a kinetic architecture, conflicted with fire restrictive options (as do open doors in smokefree evacuation routes). A compromise was adopted : the provision of generous exitways from each compartment was to compensate the extension of its size. Backed by the remedy of a short evacuation time, the maximum compartment surface was raised to $3500 \mathrm{~m} 2$, which seems to be a record in European school building.

As boarding-schools and students' homes are not subject to ulterior major alteration in space distribution, the utmost size of their compartments was limited to $2000 \mathrm{~m} 2$.

3.3. FIRE PROTECTION is above all concerned with the users' security. In this sector three major problems were dealt with : warning and alarm systems, the time needed for evacuation, the escape routes.

Obviously warning and alarm techniques vary according to the size of the school, from simple means to extensive systems, from the school bell, rang in a special way, or a portable siren, to the detector operated system showing the fire location on a synoptic panel, and in some cases combined with an automatic warning transmission to the fire station. In boarding schools each tutor(being in charge of 21 pupils) and the administrator can warn the fire station at once via a phone in their respective bedrooms. Fire alarm boxes are placed in the corridors, near each of the tutors' rooms and at an utmost distance of $60 \mathrm{~m}$ from each other; it was found practical to locate the fire-extinguishers next to these alarm-boxes.

Evacuation times: The central idea of safety concern in school building being : "Save the people and then, if possible, the building" prompted to sharp concentration on the evacuation problem.

What we wanted was a reliable computation method for future, for planned buildings, - properly speaking, a method capable to precast the evacuation time from the first design stage onwards, when it is still possible to remedy shortcomings by increasing the exiting capacity.

The major factor taken into account in our computations was the evacuation flow rate in the different escape route segments, itself being composed of several subfactors, such as the density of the evacuation stream, the width of the different escape route segments and the normal values of horizontal velocity, vertical downward velocity and vertical upward velocity. Thus we found 
three flow ratings per passage unit of $60 \mathrm{~cm}$, per second :

horizontal rate

vertical downward rate: 1,1 ) persons/passage unit/second (Ref. vertical upward rate : 0,9 ) 1 and 2)

These values, combined with the relevant interior environment factors, made it possible to compose the computing method needed to predict the evacuation time from the building design stage onwards. Moreover it includes prediction of the origin, location and duration of traffic congestions which inevitably occur at places where wider segments flow into narrower ones or at moments when the downstream evacuees are still occupying staircase segments when upstream people arrive behind them.

A description of this method would go beyond the scope of this lecture, but it should be mentioned that later on, it has been enlarged to all sorts of buildings, meeting the total agreement of the Belgian Firefighting Techniques Institute (ref. 4).

Another noteable feature was the research after what time evacuation becomes unsafe or impossible. The analysis of numerous tests and real fires seemed to show that there is no general answer. Yet we found a series of 5 co-efficlents (total surface area, number of floors, degree of space partitioning, density of occupation, equipment or production risks), the combined impact of which brought us to recommend evacuation of a school building in less than 5 , and a boarding school or studenthome in less than 7 minutes. Up to now, in fire drills, evacuation times have not exceeded $31 / 2$ and $51 / 2$ minutes respectively.

Evidently, the third fire protection concern, escape routes, was closely linked to, and based on the evacuation time conclusions. The basic rule to ensure at least one alternative wayout in all circumstances requires skilful choice and combination of length, width, number and location of the exit ways. Thus the overall school building layout is co-governed by some dominating evacuation principles :

- The every-day traffic routes are also the escape routes.

- Avoid the need to build emergency stairs.

- Divide the building, and even each compartment, into evacuation sectors, i.e. the areas to be discharged by each staircase and each outdoor exit.

Throughout the building, these sectors should be balanced in importance according to the prognosticated number of their users.

- Avoid mixing stairway exits with those that discharge the groundfloor. This means that wherever possible, the staircase-bottom should have a doorway direct to open air.

- All stairways are completely encaged and closed by walls and doors of 1 to 2 h fire resistance, according to the height.

- The wider you plan the stairs, the fewer you have to provide, the more you further cumbersome concentrations of evacuees, the fewer are the chances to spread the alternative exit ways.

- So, whenever possible, use a stairwidth of 2 passage units with railings on both sides. Stairs of 3 passage units are dangerous, the central user having no rail protection. In case of 4 passage units, the stairs have two side and one central rallings.

3.4. All essential conclusions for renewed school conception, inclusive safety, were ready in 1970 , but two more years were needed for testing, verifying and refining several newly made opinions, methods and measures. The complete results were issued in 1972 (Ref. 1) and 74 (Ref. 2) as a self-service guideline for the School Bullding Fund.

But meanwhile the scope of the task had widened, calling for additional research on a new type of school that had sprung up in the 60-ies for special 
education of handicapped children.

\section{DISABLED PUPILS}

Let us clearly make the difference between physically handicapped children or students who attend a regular school, and communities of disabled children suffering from various handicaps and educated in special schools.

4.1. To meet the needs of the former, who are extremely rare $(+0,3 \%)$, primary schools do not cause major dificulties, since these are geñerally single-storey-buildings. If they are multi-storey, all common and special rooms are always on ground floor level, as well as a number of home rooms. This space distribution always allows to keep groups that contain handicapped pupils on the evacuation level.

As such combinations are impossible in the multistorey buildings of secondary schools, these have been or are being equipped with lifts that can hold wheelchairs. But as lifts are not to be used in case of fire, the periodical evacuation drills include precise behaviour lines and exercises for the responsible teacher and some appointed volunteers to carry the handicapped student into safety.

The permanent character of dally school life organization warrants that these measures will do. But the growing community use of schools has imported a new problem, not so widely known. It is caused by the possible presence of handicapped off-hours adolescents and adults. Our lifts can bring them to any floor. But who gets them down and out in case of fire? Who, moreover, knows about their presence and where they are?

These are our provisional measures : All handicapped are welcome, whether alone or in company, on the ground floor. But movement or sensorial impaired visitors, wanting to use parts of the premises above the evacuation level, should be accompanied by at least one person, not impaired, and should report their presence on entering and withdraw it on leaving. (Ref. 3 ).

4.2. In specific schools and boarding schools for handicapped children, the situation called for an analysis of the pupils' shortcomings as to perception, response and mobility, the negative results of which should be met by special arrangements in the layout, construction and equipment of the building. We soon discovered that it was dangerously erroneous to base on the school structure qualifications of mental or physical deficiencies, because there are many bodily handicapped among the mentally or emotionally disturbed. What really matters is to know how many pupils in each impaiment category are able to escape, without help, from a building under fire.

A close investigation in 51 special schools and boarding schools showed alarming percentages of non-ambulatory pupils among both groups of mentally and physically handicapped. This statement became the keynote of our conclustons (Ref. 4):

a. Design, construction and equipment of buildings for handicapped children and adolescents must be matched to the presence of non-ambulatory impaired among both mentally or emotionally and bodily disturbed pupils.

b. Compartments in special schools should be smaller (max. 1000 m2) and more numerous than in normal schools. They should be still smaller ( $\max .500 \mathrm{~m} 2)$ and more numerous in special boarding schools, so as to limit smoke and fire spread and to procure sheltering spaces that offer quick but provisional safety by way of horizontal egress. This evactation method corresponds with the minimal disruption system recommended for hospitals (Ref, 6).

c. As the evacuation process takes more time, and as the stay in a shelter 
comparunent may be prolonged, the fire resistance of structural and compartmentation elements should attain 1 or $2 \mathrm{~h}$, according to the number of storeys.

d. Limitations of risks call for arrangements in time and space, whereby handicapped should be located on, or not far from, the evacuation level (E) which is generally the ground floor ( 0 ), as marked in the tables below.

These tables clearly reflect the need to limit the height of special schools and boarding schools to two floors above the ground floor or evacuation level. A strong preference goes towards a single-storey design or to buildings, al1 levels of which can be evacuated horizontally to the outside.

e. In these institutes, fire drills should more than anything else aim at preparing staff members to coordinate their exiting assistance and to manage the egress procedure.

f. Finally, basing on several nightly evacuation drills, it was proposed that the boarding personnel to pupils ratio should be raised to $1-8$, whereby at least one staff member should not be groupbound.

\section{A NATIONAL NORM ON FIRE SAFETY IN BUILDINGS FOR SCHOOLS, BOARDING SCHOOLS} AND STUDENTS' HOMES.

Wishing to officialize the fire safety measures as found and applied by the SBF in regular and special educational institutions, the Belgian Institute of Normalization took them as a firm base and framework for a national. norm, issued in 1982 as NBN S 21-204 (ref. 7). It was followed by a Royal Act making its application compulsary for all new school buildings, by whomever they be erected : the State, regional or local authorities and private organizations. The rather exceptional legal statute of this norm stresses the recognition of its importance.

Yet, like al1 norms, the S 21-204 deals with forthcoming, to be built situations. About existing buildings it says that their safety conditions

\begin{tabular}{|c|c|c|c|c|c|}
\hline \multirow{5}{*}{$\begin{array}{l}\text { In day- } \\
\text { time }\end{array}$} & Disab1lity Level & -1 & 0 or $\mathrm{E}$ & +1 & +2 \\
\hline & Non-ambulatory & - & 痛 & * & - \\
\hline & Ambulatory & 象 & * & * & 蚺 \\
\hline & Visual deficiency & - & 部 & - & - \\
\hline & Auditive deflciency & $*$ & 将 & 嗦 & * \\
\hline
\end{tabular}

\begin{tabular}{|l|l|c|c|c|c|}
\hline \multirow{4}{*}{$\begin{array}{l}\text { At } \\
\text { night }\end{array}$} & Disability & -1 & Oor $\mathrm{E}$ & +1 & +2 \\
\cline { 2 - 6 } & Non-ambulatory & - & & - & - \\
\cline { 2 - 6 } & Ambulatory & - & & - & \multirow{2}{*}{} \\
\cline { 2 - 6 } & Visual deficiency & - & & - & - \\
\hline
\end{tabular}


should approach the norm's prescription in the best possible way and degree. Among the older constructions, those that were not originally built for school use prove to be the most unsafe. As it is almost impossible to improve their fire resistance and reaction, the systematic approach to raising their safety level consists of a threefold measure :

- ensuring a rapid evacuation by multiplying the exit ways,

- accelerating the alarm by means of a general detection system,

- delaying fire spread by means of sprinklers in all unoccupied spaces.

\section{NEAR FUTURE}

6.1. Multi-purpose rooms, skill and handicraft training opportunities, space for multi-tuitonal activities that partake a considerable amount of floor area, direct interaction between practice rooms, intenser mobility within leaming departments are al1 in growing demand. As a combined effect of these new characteristics, considerable segments of the horizontal escape ways will soon no more be enclosed. This calls for the forthcoming need at least to clearly mark off those specific floor areas which should be rigidly kept clear from hindrances in order to ensure their exiting function.

6.2. In a number of specialized higher technical and artistic institutes, computer rooms, broadcasting and $T . V$. studios are in rapid expansion. These environments with highly concentrated and expensive electronic equipment require dry extinguishing methods, using halon gas, on account of its characteristics (non-destructive; penetrating into inaccessible spaces; almost harmless to people).

6.3. We are not satisfied at all with the general lack of safety education in our schools. Clear and complete instructions, dating from 1975 (Ref. 8), may have brought some insight in prevention and protection, but apart from periodical fire-drills they have scarcely altered the caution pattern in daily school life. Yet, you need not be an educator to know that it is perfectly possible to introduce items of safety motivated education into the curriculum of physical training, chemistry, physics, mathematics, morals.

6.4. In relation to this shortcoming, the SBF would also like to be followed in an earlier suggestion, to create series of slides or short sequence films staged in actual schools and showing safe and unsafe behaviour and consequences. The viewing should be followed by discussions.

6.5. There is a more promising prospect of regular relations between schools and fire brigades, - a movement that has already started and that consists of pupils' visits to the fire-sation, inclusive their interviewing the fire-men; or fire officers being invited to schools, to talk on their job, evolving into a discussion on safety behaviour in the very premises.

6.6. In the technical sector, forthcoming strivings go to the extension of the direct fire brigade warning systems commanded by detection. Priority will be given, in this order, to special boarding schools and special schools, to regular boarding schools in old premises, to technical schools with chemical or nuclear sciences curriculum.

\section{CONCLUSION}

Although the aims described in this paper are common knowledge, some particular methods and results probably deserved to be stressed: the human behaviour as a starting-point; the pre-calculation of evacuation times; the utmost care given to escape routes, inclusive the complete enclosure of all staircases; the particular concern for disabled children; the edition of a national specific norm, with legal status, on firesafe school building. Sumarizing, the whole 
bulk might be reduced to three questions :

Do we build our schools safely? Undoubtedly yes, and most probably they rank among the safest on the European continent, for a range of details and refinements going beyond norms and standards ensure a better control in emergancy cases. Still, constant alertness to educational evolutions is indispensable.

But - do we safely live in our school buildings? A tiptoe answer : the hardware of our safety system is of real good quality; the software is psychologically underdeveloped. For laziness to break with wrong habits, daily inadvertance, unbelief in fire, are tremendous shortcomings in education itself.

Hence this third, somewhat vindictive, question: Why the deuce do we build schools?

\section{REFERENCES}

1. Van Bogaert, A.F.: Logica en Actie in de Scholenbouw, Ed. Stevin,Brusse1, 1972.

2. Van Bogaert, A.F.: Prospective dans la construction scolaire, Ed. Vander, Brussel and Cesson (France), 1974.

3. SBF Directorate : IDG 80.040: Naschools gebruik van normale-school-gebouwen door gehandicapten, Brussel, 1980.

4. School Building Fund : Fire prevention in Schools and Boarding Schools for Handicapped, Brusse1s, 1978 and NBSIR, Washington DC, 1980, $\mathfrak{n}^{\circ} 2070$.

5. Van Bogaert, A.F.: Fire and Evacuation Times, Evacuatietijden bij Brand, Ed. Story-Scientia, Gent, 1978 .

6. Marchant, E.W. : Escape Route Design, Edinburgh; 1975.

7. B.I.N. (Belgian Institute of Normalization) : NBN S 21-204: Fire Safety in Schools, Boarding Schools and Students' Homes, Brussel, 1982.

8. Departmental Regulations : I.M. 74.120 : Brandveiligheid in Internaten, Brusse1, 1975.

I.M. 75.040: Brandveiligheid in Scholen, Brusse1, 1975. 